\title{
In memoriam Aníbal Alamón
}

El primero de mayo 2021 falleció Aníbal Alamón, luego de una larga enfermedad. Aníbal, oriundo de Tacuarembó, médico, cardiólogo, esposo, padre, gran persona y amigo. Enfrentó su enfermedad con hidalguía, de igual manera que para resolver aquellos pacientes y estudios difíciles. Fue un cardiólogo capaz - como pocos- de realizar el manejo hemodinámico en el paciente grave; además de un profundo conocedor del postoperatorio de cirugía cardíaca. Fue un destacado docente forjador de escuela. También, "con todas las letras", amigo de los amigos y muy familiero.

Entrar a la Unidad de Cuidados Intensivos de Cirugía Cardíaca, en el Cardiocentro de la Española, era compartir un mate, discutir un caso complejo y siempre aprender con Aníbal. Así como compartir un asado con cuero en el Bragado entre varios, recordando anécdotas de lo vivido. Fue coordinador y jefe de la Unidad por muchos años, siempre afirmando que “...una unidad de postoperatorio de cirugía cardíaca es esencialmente una unidad de monitoreo hemodinámico".

Aníbal fue un profesional moderno que nunca dejó de estudiar y de cultivar la profesión, practicando la Medicina basada en la evidencia. Su entrenamiento se forjó en la Udelar, pasó por la formación en Cardiología en el Hospital de Clínicas y continuó en el Instituto Chávez de la Ciudad de México.

Médico que cultivaba la atención centrada en el paciente, con profundo sentido ético y profesional; siempre tenía un tiempo para dedicar a la familia. Enorme trabajador, de incansables jornadas. Siempre dispuesto a escuchar y ser escuchado. Profesional, humanista con un norte puesto en el bienestar del paciente.

Sus grandes pasiones dentro de la profesión fueron la ecocardiografía y la recuperación postoperatoria en cirugía cardiovascular. Otra pasión fue el campo y la vida rural. Sus travesías por el río Tacuarembó con su familia, de las que nos mostraba fotografías con su sonrisa en los labios, la misma que tenía cuando nos recibía en el Bragado; un campo que arrendaba y era lugar de encuentro de amigos y colegas.

Apasionado del carnaval, supo salir campeón de las llamadas en la comparsa lubola Cuareim 1080, y cumplió uno de sus sueños: tamborilear en una cuerda campeona. Luego, tuvimos como paciente al dueño de la comparsa y Aníbal se encargó, junto al equipo anestésico-quirúrgico, de que todo se resolviera de manera adecuada. Siempre supo armonizar la Cardiología Intensiva y la Ecocardiografía con la vida social y rural.

Fue un ecografista de referencia en la Asociación Española para tantos pacientes y médicos. Desarrolló la técnica en toda su extensión poniendo saber, conocimiento y trabajo. Se entrenó y enseñó en las técnicas de eco stress, fue uno de los técnicos de mayor reconocimiento en el medio y generó escuela. Sus informes profundos, precisos y detallados quedan en el recuerdo de todos. Supo desarrollar esta técnica en otros centros, como en el Sanatorio Americano, en la ciudad de Minas, Rosario y otros sitios del interior.

Fue sin dudas un hombre cabal, frontal, conocedor de su profesión, que ejercía su liderazgo desde su saber, su bonhomía y sus profundas convicciones. La historia de la UCICC está indisolublemente asociada a Aníbal, sus protocolos, sus pautas, su equipo. Unidad reconocida en el medio, donde se lo vincula como de los mejores en su área. Conocimiento y agudeza clínica; sagacidad y esmero, siempre al servicio de los pacientes.

Imborrable aquella tardecita de enero, cuando estaba de licencia y en bermudas y pasó a buscar algo olvidado, mientras había varios colegas intentando resolver un caso difícil y él se hizo cargo, dando seguridad. 
Una persona sin formalidades, sin solemnidad, con honestidad incondicional, humildad y lealtad. Luchador incansable, trabajó hasta hace pocas semanas a pesar de todo, y jamás perdió el humor que lo caracterizaba.

Supo dejar un enorme legado a quienes tuvimos la fortuna de conocerlo y aprender de él, al haber sido uno de los pioneros de la cardiología crítica en el Uruguay. Respetado, admirado y querido por muchos, y un referente en lo personal y en lo técnico.

"Caminar a solas es posible, pero el buen andariego sabe que el gran viaje es el de la vida y requiere compañeros", como dice Helder Cámara. Aníbal, fuiste un gran compañero y amigo. En este obituario quisimos recordar al Dr. Aníbal Alamón, apreciado y querido por tantos; un cardiólogo a cabalidad, clínico, imagenólogo especialista en Cardiología Crítica. Vamos a echar de menos tus consejos, tus recuerdos, tu fuerza y tu alegría, pero te recordaremos por siempre.

Juan José Paganini Prof. Adj. de Cirugía Cardíaca, cirujano cardiovascular del Cardiocentro de la Asociación Española. Correo electrónico: jjpaganini@gmail.com

Álvaro Rivara

Ex Prof. Adj. de Cardiología, médico de la Unidad de Postoperatorio de Cirugía Cardíaca del Cardiocentro de la Asociación Española. Correo electrónico: alvarorivara@yahoo.com.ar 